\title{
Grit, Mindset, and Academic Performance: A Study of Pre- University Science Students
}

\author{
Paul Bazelais ${ }^{1}$, David John Lemay ${ }^{1}$, Tenzin Doleck ${ }^{1 *}$, Xiao Shen $\mathrm{Hu}^{1}$, Anh $\mathrm{Vu}{ }^{1}$, Jacqueline Yao ${ }^{1}$ \\ ${ }^{1}$ McGill University, Montreal, Quebec, CANADA
}

Received 6 March 2018 • Revised 31 July 2018 • Accepted 3 August 2018

\begin{abstract}
Recent studies in educational psychology highlight the role of motivational variables such as trait-like perseverance. Studies have linked such variables (e.g., grit and mindset) to academic performance. However, research has reported inconsistent findings in explaining academic achievement differences. Drawing from a sample of pre-university students $(N=309)$, the present study assesses the efficacy of both grit and mindset in predicting academic achievement. The results suggest that neither grit, nor mindset was predictive of academic achievement. These findings have significant theoretical and practical implications.
\end{abstract}

Keywords: grit, mindset, college students, academic performance

\section{INTRODUCTION}

Duckworth's appearance at the TED conference, and concurrent publication of the bestselling Grit: The Power of Passion and Perseverance, has incited popular interest in the topic of grit, defined by Duckworth, Peterson, Matthews, and Kelly (2007) as "perseverance and passion for long-term goals" (p. 1087). Grit has been promoted as an important factor in explaining achievement and persistence (Duckworth et al., 2007). However, a similar construct, mindset, has received much attention as well. The idea of mindset, "beliefs people have about the nature of human characteristics" (Murphy \& Dweck, 2016, p. 127), was popularized by Dweck (2006), who posited that mindsets can affect one's motivation, and in turn, can have an impact on academic resilience and performance. Both grit (e.g., Duckworth et al., 2007; Strayhorn, 2013) and mindset (Claro, Paunesku, \& Dweck, 2016; McCutchen, Jones, Carbonneau, \& Mueller, 2016) have been linked to academic achievement. However, the recent literature on the link between these motivational constructs and academic performance has reported mixed findings (Bazelais, Lemay, \& Doleck, 2016; West et al., 2016).

Despite the enthusiasm for these constructs, a better understanding of the link between grit, mindset, and academic performance is necessary to justify the implementation of programs and even the possibility of fostering such trait-like constructs. Many jurisdictions have begun implementing grit and mindset training programs in the face of incomplete evidence and unsubstantiated claims. Critics have also pointed out systemic issues such as socialeconomic status and questions of exclusion and racializing minorities and argue that a lack of grittiness or improper mindset blames the victims of historical marginalization rather than addressing the structural factors underlying poor academic performance of historically disadvantaged populations. The present study extends this work by assessing the relationship between grit, mindset, and academic performance. In the next section, we elaborate on both grit and mindset.

\footnotetext{
(C) 2018 by the authors; licensee Modestum Ltd., UK. This article is an open access article distributed under the terms and conditions of the Creative Commons Attribution License (http://creativecommons.org/licenses/by/4.0/). \paul.bazelais@mail.mcgill.ca $\boldsymbol{Q}$ david.lemay@mail.mcgill.ca

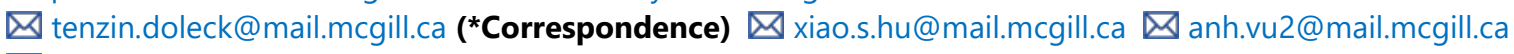
$\triangle$ jacqueline.yao@mail.mcgill.ca
} 


\section{Contribution of this paper to the literature}

- The present study explored the link between grit, mindset, and academic performance.

- Results from this study suggest that neither grit, nor mindset was predictive of academic performance.

- The findings have implications for grit and mindset training programs.

\section{LITERATURE REVIEW}

\section{Grit and Academic Performance}

Grit is defined as "perseverance and passion for long-term goals" and was presented as a trait that was shared by leaders in various fields (Duckworth et al., 2007). Aside from working diligently in face of adversity, gritty individuals demonstrate long-term stamina, an attribute not encompassed by conscientiousness. While the connection between discipline and accomplishment is not a new idea (James, 1907), the high volume of empirical research showing positive relationships between grit and entrepreneurial performance (Mueller, Wolfe, \& Syed, 2017), job retention in various professions (Robertson-Kraft \& Duckworth, 2014; Winkler, Shulman, Beal, \& Duckworth, 2014), and lasting marriages (Winkler et al., 2014), warrants investigation into grit's ability to predict academic performance.

While mental acuity has been continuously shown to predict academic achievement (Colom \& Flores-Mendoza, 2006; Pluck, Ruales-Chieruzzi, Paucar-Guerra, Andrade-Guimaraes \& Trueba, 2016), research is directed increasingly towards the roles that non-cognitive factors, such as self-discipline and emotional intelligence, have on academic performance (Duckworth \& Seligman, 2005; Thomas, Cassady \& Heller, 2017). Of the personality factors studied, conscientiousness is consistently found to significantly correlate with both secondary and tertiary education academic outcomes (MacCann \& Roberts, 2010; Malykh, 2017; Ivcevic, 2014) and has even been suggested to predict academic performance as well as intelligence, a noteworthy finding given that the Big-Five personality model, in which conscientiousness is a trait, was not designed to help determine educational outcomes (Poropat, 2009). With no pre-existing and universally applicable non-cognitive metrics for high achievement, the personality trait grit was constructed to overlap with some aspects of conscientiousness while also paying attention to duration of efforts (Duckworth, Peterson, Matthews, \& Kelly, 2007).

\section{Grit and completion rates}

Grit was originally studied in relation to retention in West Point cadets (Duckworth et al., 2007, 2009; Maddi, Matthews, Kelly, Villarreal, \& White, 2012). New arrivals at the United States Military Academy (USMA) were administered grit questionnaires to measure their continuous pursuit of interest. The researchers also assessed past performance by obtaining participants' Whole Candidate Score (WCS), a weighted composite of the candidates' academic merits, leadership capabilities, and physical aptitude test results. Retention was represented as a dichotomous variable (with $1=$ retained and $0=$ not retained) and was determined at the end of each study's time frame. Results (Duckworth et al., 2007, 2009) showed that grit predicted completion of the USMA's rigorous summer regimen more than the WCS, self-control, academic GPA, and the Military Performance Score (MPS), an evaluation based on cadets' performance ratings and military science course grades. Similarly, grit appeared to outscore hardiness and WCS in predicting USMA retention through the first academic year (Maddi et al., 2012). Grit also showed predictive validity and had a significant effect on the physically demanding 24-day Army Special Operations Forces (ARSOF) selection course, in which candidates must have already graduated from a 30-day Special Operations Preparation Course to qualify for.

Grit's ability to modestly predict completion of military training prompted research into potential connections between grit and healthcare residency programs that face costly problems of attrition (Burkhart, Tholey, Guinto, Yeo, \& Chojnacki, 2014). After assessing 73 surgical residents' psychological states, Grit-S score, self-reported measure attrition risk, and actual attrition rates, Salles et al. (2017) found that grit did not significantly predict actual residency completion $(p=0.08)$ but was negatively associated with how often participants thought about leaving residency $(\beta=-0.99, t=-2.53, p<0.05)$. A study of pharmacy students found that Grit-S scores did not correlate with GPA, though the test had low statistical power, but did predict attainment of postgraduate fellowship and training. While there were insufficient data and relatively few participants in these studies to draw conclusions on grit's ability to predict residency completion, evidence that both medical students and current residents have above average levels of grit suggests that lasting fortitude is common in those pursuing a post-graduate medical degree (Burkhart, 2014; Kelly et al., 2017). 


\section{Grit and academic achievement}

When examining factors predicting GPA at four-year universities, the effect of grit is inconsistent, with some studies showing a definitively positive relationship (Duckworth et al., 2007; Strayhorn, 2014) while others more inconclusive (Bazelais, Lemay, \& Doleck, 2016; Chang, 2014; Jaegar, Freeman, Whalen, \& Payne, 2010; Wolters \& Hussain, 2015). Along with pioneering the grit construct, Duckworth et al. (2007) were also the first to conduct studies on grit in relation to academic achievement. Undergraduate students $(n=139)$ from the University of Pennsylvania anonymously completed the Grit Scale survey and reported, among other variables, current GPA and SAT scores. There was a modest and significant association $(r=0.25, \mathrm{p}<0.01)$ between grit scores and GPA, which is consistent with later studies (Strayhorn, 2014). Using SAT scores as a proxy for intelligence, Duckworth et al. (2007) also reported that grit was negatively associated with intelligence $(r=-0.20, p<0.03)$, although it is important to note that the SAT's test-retake nature may render it an inadequate measure of general intelligence (Coyle, 2006).

Strayhorn (2014) was interested in determining if grit could explain academic success of black male students at predominantly white institutions. Data analysis of demographic information, self-reported grades, and Grit-S scores of 140 participants revealed that after controlling for all other variables collected, grit was moderately predictive of black males' college grades (partial $r=0.25, p<0.01$ ). Grittier black males were also shown to generally have higher high school GPAs and ACT scores. Such conclusions were not drawn when the sample consisted of both female and male students of various racial demographics at a historically black community college (Nelson, 2016). Nelson's (2016) study found that neither grit nor student engagement plays a significant role in predicting academic performance.

Cross (2014) controlled for student demographic variables to test if non-traditional doctoral students' grit scores were related to current GPA. Unlike traditional doctoral students who pursue their education in brick-and-mortar institutions, their non-traditional counterparts learn through online courses and may be at an even greater risk of attrition, thus prioritizing research on factors that may attenuate dropout rates (Cross, 2014). When the Pearson correlation coefficient was computed for 669 nontraditional doctorate students' grit score and GPA, grit was slightly correlated with GPA for females but not males (Cross, 2014). The high dropout rates in distance learning programs were also of concern to Hwang et al. (2017), who attribute academic maladjustment to other obligations such as work or family. To examine the relationship between grit, personality, age, and academic maladjustment, Hwang et al. (2017) collected survey results from 509 female students at an Open University in South Korea. They found that age was positively associated with grit, which is consistent with previous studies (Duckworth et al, 2007). The relationship between the grit factor perseverance, but not consistency of interest, and student GPA was mediated through academic maladjustment.

\section{Discrepancy in findings}

The discrepancy between the two grit dimensions in predicting academic outcomes was similarly reflected in other studies, suggesting that further studies need to be conducted to examine the internal consistency between the two dimensions of grit (Chang, 2014; Maccann \& Roberts, 2010; Muenks, Wigfield, Yang, \& O'Neal, 2017; Wolters \& Hussain, 2015). Chang (2014) studied the effects of grit on incoming freshmen at a competitive four-year institution. A hierarchical multiple regression analysis found that the grit composite score is not a significant predictor of first year GPA, supplementary analysis was conducted by dividing up grit into its two subscales: (a) consistency of interest, and (b) perseverance of effort. Interestingly, a student's interest subscale score negatively predicted first year GPA $(\beta=-.11, p<.01)$, while an increase in perseverance subscale led to an increase in first year GPA $(\beta=.22, p<.01)$.

Disagreements over the consistency of interest dimension and its lack of relation to achievement have contributed to alternative definitions of the grit construct (Sturman \& Zappala-Piemme, 2017). The Grit Scale for Children and Adults (GSCA) developed by Sturman and Zappala-Piemme (2017) contains vocabulary appropriate for younger participants and proposes that grit is reflected in the ability to focus and follow through on any potential activity of interest. Robertson-Kraft and Duckworth (2014) also developed a more discrete and applicable scale for employers to assess, through résumé alone, a teacher's grit on a 7-point scale. The ability to predict teacher retention and effectiveness from grit scores coded from biographical data, beyond academic credentials and leadership potential, foreshadows use in hiring practices in addition to grit-training that has already been pushed forth in schools (Strauss, 2016).

\section{Mindset and Academic Performance}

Dweck et al. (2000) proposed that there are two types of mindset: fixed and growth mindsets. A fixed mindset means that an individual believes that ability and intelligence are unchanging whereas a growth mindset means an 
individual believes that ability and intelligence are malleable traits and can be improved and made stronger. Blackwell et al. (2007) and Romero et al. (2014) suggested that students who adopt a growth mindset are more likely to have increased academic achievement because they perceive difficult tasks and situations as opportunities for self-improvements and often seek out challenging learning environments. Miller et al. (2003) further suggested that promoting a growth mindset can help them to set goals and to persevere when encountering difficult tasks.

\section{Mindset and achievement}

Many studies have demonstrated a relationship between a growth mindset and achievement (Aronson et al., 2002; Blackwell, 2007; Burnett et al., 2013; Cury et al., 2008; Devers, 2015; Dweck et al., 2000; 2012; Good, 2003; Stipek et al., 1996; Tirri \& Kujala, 2016; Yeager \& Walton, 2011; Zeng et al., 2016). Growth mindset appears to have a direct positive impact on students' academic achievement throughout primary and secondary schools. However, the effect of mindset and academic achievement among university and college students is not well understood. While Aronson et al. (2002) concluded that growth mindset could improve academic achievements among university African American students, Devers (2015) and Bahnik and Vranka (2017) argued that there is no positive correlation between mindset and academic achievement.

Authors have argued that performance measures are indicative of an individual's intelligence (Duckworth et al., 2007; Gottfredson, 1997; Hartigan \& Wigdor, 1989; Pascarella \& Terenzini, 2005); however, it appears clear that the relationship is mediated by other situational variables outside of the students' control (Robbins, Oh, Le, \& Button, 2009). Socioeconomic status has been shown to have an impact on academic achievement (Coleman et al., 1996; Duncan et al., 2011). Claro et al. (2016) studied 10th grade public school students in Chile through a nationwide standardized test on mathematics and language skills $(\mathrm{N}=168,203$, and $\mathrm{N}=168,553$ for mathematic and language respectively) and reported that there was a strong correlation between mindset and academic performance with mindset accounting for $11.8 \%$ of the variance $(r=0.343)$ in mathematics and language scores. The authors found that students from low income families are more likely to adopt a fixed mindset than those coming from top-income families. However, students who come from 10th percentile of family income with a growth mindset exhibited academic performance as high as those in the 80th percentile of family income. Thus, Claro et al. (2016) concluded that growth mindset might dampen the deleterious effects of poverty on academic achievement.

\section{Rationale for Study}

The purpose of this study is to examine the relationship between grit, mindset, and academic achievement among college-level students.

Our research question is:

What is the relationship between grit, mindset, and academic achievement among pre-university science students enrolled at one CEGEP institution?

\section{METHOD}

\section{Procedure and Participants}

A convenience sample of students from a pre-university science program at an English Collège d'enseignement général et professionnel (CEGEP; for a review, see Bazelais, Lemay, \& Doleck, 2016) voluntarily participated in the study. Students were invited to fill out an online self-report questionnaire by the data mining office at the CEGEP. The recruitment of the samples and the study's procedure were in accordance with the ethics requirements.

In total, $N=309$ (168 female, 135 male, and 6 other) students participated in the study. Participants' average age was $21.79(S D=7.74)$. Participants completed both the Grit and Mindset questionnaires.

\section{MEASURES}

\section{Grit}

Grit was assessed using the 12-item, 5-point Likert-style (ranging from Very much like me to Not like me at all) Grit Scale Survey (Duckworth et al., 2007). The Grit Scale is a self-report survey of participants' consistency of interests and perseverance of effort through questions such as: "My interests change from year to year" and "I have overcome setbacks to conquer an important challenge" (Duckworth et al., 2007). 
Table 1. Model Summary

\begin{tabular}{|c|c|c|c|c|c|c|c|c|c|}
\hline \multirow{2}{*}{ Model } & \multirow{2}{*}{$\boldsymbol{R}$} & \multirow{2}{*}{$R^{2}$} & \multirow{2}{*}{ Adjusted $R^{2}$} & \multirow{2}{*}{$\begin{array}{l}\text { Std. Error of } \\
\text { the Estimate }\end{array}$} & \multicolumn{5}{|c|}{ Change Statistics } \\
\hline & & & & & $R^{2}$ Change & F Change & $d f_{1}$ & $d f_{2}$ & Sig. $F$ Change \\
\hline 1 & $.542^{\mathrm{a}}$ & .294 & .286 & 7.75904 & .294 & 40.863 & 3 & $295^{a}$ & .000 \\
\hline 2 & $.545^{b}$ & .297 & .288 & 7.75275 & .004 & 1.479 & 1 & $294^{b}$ & .225 \\
\hline
\end{tabular}

a. Predictors: (Constant), H.S. GPA, Age, Gender

b. Predictors: (Constant), H.S. GPA, Age, Gender, Grit

Table 2. Summary of Hierarchical Multiple Regression Analysis

\begin{tabular}{lcccc}
\hline & $\boldsymbol{B}$ & $\boldsymbol{S E}-\boldsymbol{b}$ & $\boldsymbol{t}$ & $\boldsymbol{B}$ \\
\hline Age & .556 & .063 & 8.806 & $.447^{\star}$ \\
\hline Gender & -.647 & .863 & -.750 & -.038 \\
\hline H.S. GPA & .474 & .067 & 7.081 & $.352^{\star}$ \\
\hline Grit & -.961 & .791 & -1.216 & -.061 \\
\hline
\end{tabular}

\section{Mindset}

Both fixed and growth mindsets were assessed using the 16-item, 6-point Likert style (ranging from Strongly Agree to Strongly Disagree) Mindset Survey (Mindset, 2018). Example items: "You have a certain amount of intelligence, and you can't really do much to change it" and "No matter how much talent you have, you can always change it quite a bit".

\section{Academic Performance}

Academic performance was measured using students' overall $R$-Score, which is "an indicator of that student's rank in the group based on that individual's grade (the $\mathrm{Z}$ score), and an indicator of the relative strength of that group (ISG)" for each course (CREPUQ, 2007, p. 6).

\section{ANALYSES AND RESULTS}

\section{Grit and Academic Performance}

A hierarchical multiple linear regression was performed to test for the effects of grit scores on CEGEP academic performance, while controlling for age, gender, and high-school GPA. The assumptions for hierarchical multiple linear regression were met. The model summary is presented in Table 1. Age, gender, and high school GPA were entered first into the model (control variables), followed by the IV of interest (grit scores) and academic performance (CEGEP GPA) serving as the DV. The first block of IV (age, gender, and high school GPA) explained approximately $29.4 \%$ of the variance in academic performance $\left(R^{2}=.294\right)$ and was found to be significant, $F(3,295)=40.863$, $p<0.001$.

When the grit scores were included in the second block, the model as a whole explained approximately $29.7 \%$ of the variance in academic performance $\left(R^{2}=.297\right)$. The results indicated that grit was not a significant predictor of academic performance $\left(R^{2}\right.$ change $=.004 ; F$ change $\left.(1,294)=1.479, p=.225\right)$. Whereas, the overall model was found to be significant, $F(4,294)=31.067, \mathrm{p}<0.001$. Individually, only age $(\beta=.556)$ and high-school GPA $(\beta=.474)$ were significant predictors of academic performance (see Table 2).

\section{Mindset and Academic Performance}

A one-way analysis of covariance (ANCOVA) was conducted to test the difference between various levels of mindset on students' CEGEP GPA whilst controlling for age, gender, and high-school GPA. The independent variable mindset has three levels: fixed, growth, and fixed-growth. The dependent variable was CEGEP GPA and the covariates were: age, gender, and high-school GPA. The assumptions for ANCOVA were met. The summary of tests of between-subjects effects is presented in Table 3. There was no significant effect for mindsets on CEGEP GPA, $F(2,293)=.265, p=.767$, after controlling for age, gender, and high-school GPA. 
Table 3. Tests of Between-Subjects Effects

\begin{tabular}{lcccccc}
\hline Source & Type III Sum of Squares & df & Mean Square & F & Sig. & Partial Eta Squared \\
\hline Corrected Model & $7412.254^{\mathrm{a}}$ & 5 & 1482.451 & 24.502 & .000 & .295 \\
\hline Intercept & 750.024 & 1 & 750.024 & 12.396 & .000 & .041 \\
\hline Age & 4589.346 & 1 & 4589.346 & 75.852 & .000 & .206 \\
\hline Gender & 33.548 & 1 & 33.548 & .554 & .457 & .002 \\
\hline HS GPA & 2826.564 & 1 & 2826.564 & 46.717 & .000 & .138 \\
\hline Mindset & 32.106 & 2 & 16.053 & .265 & .767 & .002 \\
\hline Error & 17727.692 & 293 & 60.504 & & & \\
\hline Total & 272157.720 & 299 & & & & \\
\hline Corrected Total & 25139.947 & 298 & & &
\end{tabular}

\section{DISCUSSION}

A cursory reading of literature suggests an unambiguous link between growth mindset, grit, and achievement. However, recent meta-analytic work suggests the relationship is more complicated. A recent meta-analysis (Sisk, Burgoyne, Sun, Butler, \& Macnamara, 2018) of the relationship between mindset and achievement found only a small correlation between the two $(r=.1)$ and a small effect $(d=.08)$ of growth mindset interventions, and only for at-risk and lower SES students. Mindset interventions were non-significant for adolescents and regular students. In another recent meta-analysis (Credé, Tynan, \& Harms, 2017) looking at the relationships between grit and performance, retention, and student characteristics such as personality factors, cognitive ability, including 548 effects sizes representing more than 66,000 individuals, the authors were not able to confirm the grit factor structure. Perseverance of effort had significantly stronger criterion validity compared to consistency of effort. Moreover, the authors found that perseverance was only moderately correlated with performance and retention, but strongly correlated with conscientiousness, as has been shown elsewhere (Komarraju, Karau, \& Schmeck, 2009). These findings are replicated in our results here. Indeed, in another meta-analytic study (Robbins, Oh, Le, \& Button, 2009) performance and retention were found to be strongly correlated $(r=.44)$ and the link between intervention strategies, such as providing academic support, socialization, self-management skills, and first-year experiences, and retention was mediated by psychosocial factors including emotional, motivational, and social control. Taken together, these findings suggest that the link between perseverance and retention is much more complex than grit theorists propose.

In the present study, neither grit, nor mindset was predictive of academic achievement for college-level students at one CEGEP institution, after controlling for HS GPA. This is unsurprising as high school GPA is widely reported as an important predictor of college performance (Bazelais, Lemay, \& Doleck, 2018). While this doesn't invalidate the existence of a relationship between GPA and grit and mindset outright, it does suggest that both grit and mindset constructs may be to some extent overlapping with GPA. In other words, prior performance appears as a better predictor of achievement than grit or mindset and the predictive ability of grit and mindset are offset by measures of prior performance. Although one must be careful not to infer this as evidence for trait likecharacteristic, because high schools and CEGEPs as institutions share much more in common than they differ. Indeed, the predictive quality of HS GPA to college GPA is likely partly accounted for by the similarities between these two educational contexts. However, studies have also raised issue with the stability of grit over the transition from high school to college (Muenks, Wigfield, Yang, \& O'Neil, 2017). The predictive quality of prior performance is likely due to both cognitive-affective traits and situational determinants of performance (e.g., instructional design, learning environment, workload, etc.). Moreover, studies have reported that other motivational factors such as self-regulation are better predictors than grit (Muenks, Wigfield, Yang, \& O'Neil, 2017; Wolters \& Hussain, 2015). Finally, it may be that both grit and mindset are influenced by the development of perceived competence. For instance, one study (Gonida et al., 2006) found that fifth and sixth graders' mindset is influenced by previous achievement level through the development of perceived competence. In other words, high achievers' mindsets were found to be more growth oriented compared to medium achievers and low achievers. This suggests that grit and mindset may be somewhat self-fulfilling prophecies, and that early success may beget later success. Further, if grit and mindset indeed have trait-like characteristics, as with conscientiousness and other personality traits these may be determined fairly early in students' academic trajectory.

Indeed, Devers (2015) conducted a study consisting of ten undergraduate students and twenty-two high school students, all enrolled at the STEM Academy, and found no difference in student mindsets before and after raising awareness about mindset. For both high school and college students, there was no significant difference in mindset before and after the intervention. Other college-level studies (Bahnik \&Vranka, 2017; Bazelais, Lemay, \& Doleck, 2016; Sriram, 2014) have not found significant relationships between growth mindset or grit and academic performance concluding that mindset and grit do not predict academic achievement at the college level. Thus, it 
may be that mindset is no more a discerning factor at the college level than what is already accounted for by students' prior academic performance.

\section{Limitations}

This study has some notable limitations, namely the use of convenience sampling, self-report instruments, and a cross-sectional research design.

\section{Conclusions and Future Directions}

The objective of the present study was to test the relationship between grit, mindset, and academic achievement. After controlling for the prior academic performance, we found that grit and mindset were not associated with academic achievement. Prior academic performance in high school is a strong predictor of academic achievement at the college-level (Bazelais, Lemay, \& Doleck, 2018). This study has important implications for educational researchers and policymakers as it suggests that targeting grit or mindset at the college level may not improve students' academic achievement. Nonetheless, appealing to non-cognitive motivational factors such as perseverance and personal growth may encourage other prosocial habits and attitudes and improve academic performance indirectly. Future research concerning the relationship between non-cognitive motivational factors and academic achievement should attempt to map their development over time, and ought to consider other personality traits such as conscientiousness, which have also been related to academic achievement.

\section{REFERENCES}

Aronson, J., Fried, C. B., \& Good, C. (2002). Reducing the Effects of Stereotype Threat on African American College Students by Shaping Theories of Intelligence. Journal of Experimental Social Psychology, 38, 113-125. https:/ / doi.org/10.1006/jesp.2001.1491

Bahník, Š., \& Vranka, M. (2017). Growth mindset is not associated with scholastic aptitude in a large sample of university applicants. Personality and Individual Differences, 117, 139-143. https:// doi.org/10.1016/j.paid.2017.05.046

Bazelais, P., Lemay, D. J., \& Doleck, T. (2016). How Does Grit Impact Students' Academic Achievement in Science? European Journal of Science and Mathematics Education, 4(1), 33-43.

Bazelais, P., Lemay, D. J., \& Doleck, T. (2018). Examining the Link between Prior Achievement in Secondary Education and Performance in College: Using Data from Pre-University Physics Courses. Journal of Formative Design in Learning. Advance online publication. https:/ / doi.org/10.1007/s41686-018-0020-x

Blackwell, L. S., Trzesniewski, K. H., \& Dweck, C. S. (2007). Implicit Theories of Intelligence Predict Achievement across an Adolescent Transition: A Longitudinal Study and an Intervention. Child Development, 78, 246-263. https:/ / doi.org/10.1111/j.1467-8624.2007.00995.x

Burkhart, R. A., Tholey, R. M., Guinto, D., Yeo, C. J., \& Chojnacki, K. A. (2014). Grit: A marker of residents at risk for attrition? Surgery, 155(6), 1014-1022. https:/ / doi.org/10.1016/j.surg.2014.01.015

Burnette, J. L., Oboyle, E. H., Vanepps, E. M., Pollack, J. M., \& Finkel, E. J. (2013). Mind-sets matter: A meta-analytic review of implicit theories and self-regulation. Psychological Bulletin, 139(3), 655-701. https://doi.org/10.1037/a0029531

Chang, W. (2014). Grit and academic performance: Is being grittier better? (Unpublished doctoral dissertation). University of Miami, Florida.

Claro, S., Paunesku, D., \& Dweck, C. (2016). Growth mindset tempers the effects of poverty on academic achievement. Proceedings of The National Academy Of Sciences, 113(31), 8664-8668. https:/ / doi.org/10.1073/pnas.1608207113

Coleman, J. S., et al. (1966). Equality of Educational Opportunity (US Government Printing Office, Washington, DC), 1066-5684.

Colom, R., \& Flores-Mendoza, C. E. (2007). Intelligence predicts scholastic achievement irrespective of SES factors: Evidence from Brazil. Intelligence, 35(3), 243-251. https:// doi.org/10.1016/j.intell.2006.07.008

Credé, M., Tynan, M. C., \& Harms, P. D. (2017). Much ado about grit: A meta-analytic synthesis of the grit literature. Journal of Personality and Social Psychology, 113(3), 492-511. https:/ / doi.org/10.1037/pspp0000102

CREPUQ. (2007). The R score: what it is, and what it does (pp. 1-18). Retrieved from http:/ /www.johnabbott.qc.ca/wpcontent/uploads/2014/05/R_score_what_it_is_English.pdf 
Cury, F., Da Fonseca, D., Zahn, I., \& Elliot, A. (2008). Implicit Theories and IQ Test Performance: A Sequential Mediational Analysis. Journal of Experimental Social Psychology, 44, 783-791. https:/ / doi.org/10.1016/j.jesp.2007.07.003

Devers, A. (2015). Thinking about Intelligence: How Student Mindsets Influence Academic Performance. Rising Tide, 7. Retrieved from http://www.smcm.edu/mat/wp-content/uploads/sites/73/2015/06/AllysonDevers-2015.pdf

Duckworth, A. L., \& Quinn, P. D. (2009). Development and validation of the short grit scale (grit-s). Journal of Personality Assessment, 91(2), 166-174. https:/ / doi.org/10.1080/00223890802634290

Duckworth, A. L., \& Seligman, M. E. P. (2005). Self-discipline outdoes IQ in predicting academic performance of adolescents. Psychological Science, 16(12), 939-944. https:/ / doi.org/10.1111/j.1467-9280.2005.01641.x

Duckworth, A. L., Peterson, C., Matthews, M. D., \& Kelly, D. R. (2007). Grit: Perseverance and passion for longterm goals. Journal of Personality and Social Psychology, 92(6), 1087-1101. https://doi.org/10.1037/00223514.92.6.1087

Dweck, C. S. (1999). Self-theories: Their role in motivation, personality, and development. Philadelphia, PA: Psychology Press.

Dweck, C. S. (2000). Self-Theories: Their Role in Motivation, Personality, and Development. Philadelphia, PA: Psychology Press.

Dweck, C. S. (2006). Mindset: The new psychology of success. New York: Random House Incorporated.

Dweck, C. S. (2012). Mindsets and Human Nature: Promoting Change in the Middle East, the Schoolyard, the Racial Divide, and Willpower. American Psychologist, 67, 614. https://doi.org/10.1037/a0029783

Eskreis-Winkler, L., Shulman, E. P., Beal, S. A., \& Duckworth, A. L. (2014). The grit effect: predicting retention in the military, the workplace, school and marriage. Frontiers in Psychology, 5. https:/ / doi.org/10.3389/fpsyg.2014.00036

Farruggia, S. P., Han, C., Watson, L., Moss, T. P., \& Bottoms, B. L. (2016). Noncognitive Factors and College Student Success. Journal of College Student Retention: Research, Theory \& Practice. Advance online publication. https:/ / doi.org/10.1177/1521025116666539

Gonida, E., Kiosseoglou, G., \& Leondari, A. (2006). Implicit Theories of Intelligence, Perceived Academic Competence, and School Achievement: Testing Alternative Models. The American Journal of Psychology, 119, 223-238. https:// doi.org/10.2307/20445336

Good, C., Aronson, J., \& Inzlicht, M. (2003). Improving Adolescents' Standardized Test Performance: An Intervention to Reduce the Effects of Stereotype Threat. Journal of Applied Developmental Psychology, 24, 645662.

Gottfredson, L. S. (1997). Why grit matters: The complexity of everyday life. Intelligence, 24, 79-132.

Hartigan, J., \& Wigdor, A. (1989). Fairness in employment testing: Validity generalization, minority issues, and the general aptitude test battery. Washington, DC: National Academy Press.

Hwang, M. H., Lim, H. J., \& Ha, H. S. (2017). Effects of Grit on the Academic Success of Adult Female Students at Korean Open University. Psychological Reports. Advance online publication. https://doi.org/10.1177/0033294117734834

Ivcevic, Z., \& Brackett, M. (2014). Predicting school success: Comparing Conscientiousness, Grit, and Emotion Regulation Ability. Journal of Research in Personality, 52, 29-36. https:/ / doi.org/10.1016/j.jrp.2014.06.005

Jaeger, B., Freeman, S., Whalen, R., \& Payne, R. (2010, June). Successful Students: Smart or Tough? Paper presented at 2010 Annual Conference \& Exposition, Louisville, Kentucky. Retrieved from https:/ / peer.asee.org/16281

James, W. (1907). The Energies of Men. The Philosophical Review, 16(1), 1-20. https:/ / doi.org/10.2307/2177575

Kelly, A. M., Townsend, K. W., Davis, S., Nouryan, L., Bostrom, M. P. G., \& Felix, K. J. (2017). Comparative Assessment of Grit, Conscientiousness, and Self-Control in Applicants Interviewing for Residency Positions and Current Orthopaedic Surgery Residents. Journal of Surgical Education. https://doi.org/10.1016/j.jsurg.2017.09.002

Komarraju, M., Karau, S. J., \& Schmeck, R. R. (2009). Role of the Big Five personality traits in predicting college students' academic motivation and achievement. Learning and Individual Differences 19(1), 47-52.

Maccann, C., \& Roberts, R. (2010). Do time management, grit, and self-control relate to academic achievement independently of conscientiousness? 79-90.

Maddi, S., Matthews, M. D., Kelly, D. R., Villarreal, B., \& White, M. (2012). The Role of Hardiness and Grit in Predicting Performance and Retention of USMA Cadets. Military Psychology, 24(1), 19-28. https:/ / doi.org/10.1080/08995605.2012.639672 
Malykh, S. (2017). The role of Personality Traits and Intelligence in Academic Achievement of Russian High School Students. Procedia - Social and Behavioral Sciences, 237, 1304-1309. https:// doi.org/10.1016/j.sbspro.2017.02.214

McCutchen, K., Jones, M., Carbonneau, K., \& Mueller, C. (2016). Mindset and standardized testing over time. Learning and Individual Differences, 45, 208-213. https:/ / doi.org/10.1016/j.lindif.2015.11.027

Miller, G. (2013). Understanding John Hattie's visible learning research in the context of Carol Dweck's growth mindset (Training notes). Retrieved from http:/ / growthmindseteza.org/files/hattie_Dweck_2012.doc

Mindset. (2018). Mindsetonline.com. Retrieved from https://mindsetonline.com/testyourmindset/step1.php

Mouratidis, A., Michou, A., \& Vassiou, A. (2017). Adolescents' Autonomous Functioning and Implicit Theories of Ability as Predictors of Their School Achievement and Week- to-Week Study Regulation and Well-Being. Contemporary Educational Psychology, 48, 56-66.

Mueller, B. A., Wolfe, M. T., \& Syed, I. (2017). Passion and grit: An exploration of the pathways leading to venture success. Journal of Business Venturing, 32(3), 260-279. https:/ / doi.org/10.1016/j.jbusvent.2017.02.001

Muenks, K., Wigfield, A., Yang, J. S., \& O’Neal, C. R. (2017). How True Is Grit? Assessing Its Relations to High School and College Students' Personality Characteristics, Self-Regulation, Engagement, and Achievement. Journal of Educational Psychology, 109(5), 599-620. https://doi.org/10.1037/edu0000153

Murphy, M., \& Dweck, C. (2016). Mindsets shape consumer behavior. Journal of Consumer Psychology, 26(1), 127136. https:// doi.org/10.1016/j.jcps.2015.06.005

Nelson, S. M. (2016). Grit, Student Engagement, and Academic Performance at a Historically Black Community College (Doctoral Dissertation). Retrieved from https://scholarlyrepository.miami.edu/cgi/viewcontent.cgi? referer=https: / $/$ www.google.ca $/$ \&httpsredir=1\&article=2319\&context=oa_dissertations

Pascarella, E. T., Terenzini, P. T. (2005). How college affects students: Vol 2. A third decade of research. San Francisco, CA: Jossey-Bass.

Pluck, G., Ruales-Chieruzzi, C. B., Paucar-Guerra, E. J., Andrade-Guimaraes, M. V., \& Trueba, A. F. (2016). Separate contributions of general intelligence and right prefrontal neurocognitive functions to academic achievement at university level. Trends in Neuroscience and Education, 5(4), 178-185. https:// doi.org/10.1016/j.tine.2016.07.002

Poropat, A. E. (2014). A meta-analysis of adult-rated child personality and academic performance in primary education. British Journal of Educational Psychology, 84(2), 239-252. https:/ / doi.org/10.1111/bjep.12019

Reardon, S. F. (2011). The widening of the socioeconomic status achievement gap: New evidence and possible explanations. Whither opportunity? Rising inequality, schools, and children's life chan. In G. J. Duncan \& R. J. Murnane (Eds.), Whither opportunity? Rising inequality, schools, and children's life chances (pp. 91-116). New York: Russell Sage Foundation.

Robbins, S. B., Oh, I.-S., Le, H., \& Button, C. (2009). Intervention effects on college performance and retention as mediated by motivational, emotional, and social control factors: Integrated meta-analytic path analyses. Journal of Applied Psychology, 94(5), 1163-1184. https:/ / doi.org/10.1037/a0015738

Robertson-Kraft, C., \& Duckworth, A. L. (2014). True Grit: Trait-level Perseverance and Passion for Long-term Goals Predicts Effectiveness and Retention among Novice Teachers. Teachers College Record (1970), 116(3). Retrieved from https:/ /www.ncbi.nlm.nih.gov/pmc/articles/PMC4211426/

Romero, C., Master, A., Paunesku, D., Dweck, C. S., \& Gross, J. J. (2014). Academic and Emotional Functioning in Middle School: The Role of Implicit Theories. Emotion, 14, 227. https:/ / doi.org/10.1037/a0035490

Salles, A., Lin, D., Liebert, C., Esquivel, M., Lau, J. N., Greco, R. S., \& Mueller, C. (2017). Grit as a predictor of risk of attrition in surgical residency. The American Journal of Surgery, 213(2), $288-291$. https:// doi.org/10.1016/j.amjsurg.2016.10.012

Sisk, V., Burgoyne, A., Sun, J., Butler, J., \& Macnamara, B. (2018). To What Extent and Under Which Circumstances Are Growth Mind-Sets Important to Academic Achievement? Two Meta-Analyses. Psychological Science. https:/ / doi.org/10.1177/0956797617739704

Sriram, R. (2014). Rethinking Intelligence: The Role of Mindset in Promoting Success for Academically High-Risk Students. Journal of College Student Retention: Research, Theory $\mathcal{E}$ Practice, 15(4), 515-536. https://doi.org/10.2190/CS.15.4.c

Stipek, D., Gralinski, J. H. (1996). Children's beliefs about intelligence and school performance. Journal of Educational Psychology, 88(3), 397-407.

Strauss, V. (2016, May 10). The problem with teaching 'grit' to poor kids? They already have it. Here's what they really need. Washington Post. Retrieved from https://www.washingtonpost.com/news/answer- 
sheet/wp/2016/05/10/the-problem-with-teaching-grit-to-poor-kids-they-already-have-it-heres-whatthey-really-need/

Strayhorn, T. (2013). What Role Does Grit Play in the Academic Success of Black Male Collegians at Predominantly White Institutions? Jour. of African American Studies, 18(1), 1-10. https:/ / doi.org/10.1007/s12111-012-9243-0

Sturman, E. D., \& Zappala-Piemme, K. (2017). Development of the grit scale for children and adults and its relation to student efficacy, test anxiety, and academic performance. Learning and Individual Differences, 59, 1-10. https:/ / doi.org/10.1016/j.lindif.2017.08.004

Thomas, C. L., Cassady, J. C., \& Heller, M. L. (2017). The influence of emotional intelligence, cognitive test anxiety, and coping strategies on undergraduate academic performance. Learning and Individual Differences, 55, 4048. https:// doi.org/10.1016/j.lindif.2017.03.001

Tirri, K., Kujala, T. (2016). Students' Mindsets for Learning and Their Neural Underpinnings. Psychology, 7, 1231. https:/ / doi.org/10.4236/psych.2016.79125

West, M., Kraft, M., Finn, A., Martin, R., Duckworth, A., Gabrieli, C., \& Gabrieli, J. (2016). Promise and Paradox. Educational Evaluation and Policy Analysis, 38(1), 148-170. https:/ / doi.org/10.3102/0162373715597298

Wolters, C. A., \& Hussain, M. (2015). Investigating grit and its relations with college students' self-regulated learning and academic achievement. Metacognition and Learning, 10(3), 293-311. https:/ / doi.org/10.1007/s11409-014-9128-9

Yeager, D. S., \& Walton, G. M. (2011). Social-Psychological Interventions in Education: They're Not Magic. Review of Educational Research, 81, 267-301. https:/ / doi.org/10.3102/0034654311405999

Zeng, G., Hou, H., \& Peng, K. (2016). Effect of Growth Mindset on School Engagement and Psychological WellBeing of Chinese Primary and Middle School Students: The Mediating Role of Resilience. Frontiers in Psychology, 7, 1873. https:// doi.org/10.3389/fpsyg.2016.01873

\section{http://www.ejmste.com}

